\title{
El derecho y los animales: existen razones suficientes para negarles la categoría jurídica de ser objeto de derecho y poder ser considerados sujetos de derecho
}

Beatriz Franciskovic Ingunza

Universidad Científica del Sur

\section{RESUMEN}

Por medio del presente artículo se realiza un análisis de cómo son considerados y tratados los animales frente al derecho, y de esa manera reflexionar si pueden seguir siendo objetos o pueden ser considerados como sujetos de derecho, sujetos especiales del derecho o sujetos a una protección especial.

\section{PALABRAS CLAVE}

Animales, categoría jurídica, objeto de derecho, sujeto de derecho.

\section{ABSTRACT}

By means of this article is an analysis of how they are regarded and treated the animals against the law and so may still consider whether objects or can be considered as subjects of law or special subject or subjects of the right to protection Special.

\section{KEY WORDS}

Animals, legal category, subject to the right, subject to law. 


\section{Introducción}

Para empezar, no puedo dejar de reconocer y mencionar la impresionante y valiosa investigación realizada por don Alfredo González Prada, con la tesis denominada El derecho y el animal, que sustentó en la Universidad Nacional Mayor de San Marcos para obtener el título de doctor en Jurisprudencia, allá por el año 1914. En este trabajo de investigación el autor no solo deja plasmados sus grandes y profundos conocimientos de las tendencias y doctrinas jurídicas, sino que denota y refleja su gran calidad, esfuerzo y profundidad de ser humano, así como su cultura, preparación, conocimiento y elegancia en manifestar sus ideas, opiniones y conclusiones, asentadas en razones fundadas, sin temor, con amor, pasión y respeto.

\section{Los animales desde una mirada del ordenamiento jurídico}

Iniciaremos formulándonos algunas preguntas, que serán resueltas al final de este breve artículo. ¿Qué consideraciones nos llevan a pensar sobre la imposibilidad de considerar a los animales como sujetos de derecho? ¿Somos acaso los animales humanos seres superiores a los animales no humanos? ¿Debemos seguir considerando a los animales como objeto de derecho?

Para contestar estas preguntas abordaremos lo concerniente a la bifurcación que existe entre los términos sujeto y objeto de derecho, así como las corrientes y tendencias respecto a las diferencias y semejanzas con los animales.

En cuanto a la perspectiva del derecho, y sin el afán de conceptualizar o delimitar su definición, contenido o elementos, no podemos dejar de admitir que desde una perspectiva normativista sistemática este busque, entre otros fines, regular o reglamentar conductas humanas, con el fin de poder coexistir con los demás, y convivir en paz, orden y sosiego.

Empero, partiendo de la idea de que, efectivamente, una de las múltiples finalidades del derecho consiste en lograr una armónica coexistencia con los demás seres humanos, nos preguntamos por el hecho de que acaso este fin del derecho deba necesaria y exclusivamente excluir a los otros seres no humanos - a los animales - seres tan vivos como los humanos —animales humanos-. Consideramos que esto no debe seguir así.

No debe seguir así justamente porque es al derecho a quien le corresponderá determinar, precisar y ampliar sus fines, sobre todo teniendo en cuenta la realidad socioeconómica cultural actual, así como las relaciones afectivas y afectivas relaciones que uno puede crear para con los animales, específicamente con los de compañía, denominados animales domésticos. 
Por ello, no descartamos que una de las finalidades del derecho se amplíe, concediendo y reconociendo una total protección y mayor grado de respeto para con los animales. Como lo expresa Roxin': "La mutabilidad del concepto de bien jurídico es ciertamente de tipo normativo; pero no es estática, sino que dentro del marco de las finalidades constitucionales está abierta al cambio social y a los progresos del conocimiento científico».

Asimismo, Jesús Mosterin, citado por Pierre Foy Valencia² ${ }^{2}$ señala:

Los derechos no existen de un modo natural, sino que se crean de un modo convencional, mediante la legislación. Las declaraciones universales de los derechos de los animales en general o de los derechos humanos en particular son declaraciones de buenas intenciones, en las que propugna la promulgación de leyes que impongan ciertas obligaciones y prohibiciones. En efecto, que algo o alguien tengan derechos significa que los demás tengan obligaciones respecto a él. Por eso pueden tener derechos sin tener obligaciones. Por ejemplo, el legislador puede conferir derechos a los bebés o a los perros, sin por ello imponerles obligaciones a ellos, sino solo a los demás (en este caso, a los padres o a los dueños). [...] No tendría sentido reclamar la libertad de prensa para los peces (que no escriben), ni la libertad de estirar las alas para los mamíferos (que no tenemos alas) ni la libertad de abortar para los hombres (que no pueden quedar preñados). Lo que sí tiene sentido es universalizar las diversas máximas morales y las diversas reclamaciones de derechos hasta su lógica conclusión, es decir, hasta alcanzar a todas las criaturas para las que son relevantes. Todos los animales capaces de sufrir (es decir, al menos todos los craniados o vertebrados, deberían tener el derecho a no ser torturados; es decir, que no se les haga sufrir innecesariamente por una interferencia nuestra. El derecho animal (y por tanto también humano) más fundamental es el derecho a no ser torturado.

\subsection{En cuanto a la categoría jurídica de ser sujeto de derecho}

Según la Real Academia Española, la expresión filosófica de sujeto significa: «Fil. Espíritu humano, considerado en oposición al mundo externo, en cualquiera de las relaciones de sensibilidad o de conocimiento, y también en oposición a sí mismo como término de conciencia. Fil. Ser del cual se predica o anuncia algo».

Según Fernández Sessarego, «El contenido ontológico de la categoría jurídica genérica de sujeto de derecho se adscribirá, única y exclusiva-

1 Claus 1997: 58

2 Foy 2010: 59. 
mente — de manera directa o indirecta—-, al ser humano en cualquiera de las etapas de su vida en relación» ${ }^{3}$.

Para nuestro ordenamiento jurídico, el término sujeto de derecho difiere del de persona. La categoría de persona hace referencia únicamente a las personas naturales o individuales (el ser humano una vez nacido) y a las personas jurídicas o colectivas (agrupación de personas individuales o colectivas que se reúnen para un determinado fin y que cumplen con todos aquellos requisitos formales que le permiten inscribirse en el registro público respectivo); empero, el termino sujeto de derecho es mucho más amplio que el de persona, pues hace referencia a cuatro categorías que estén relacionadas con la vida humana. Estos son:

1. El concebido, con la interminable e inagotable dificultad e incerteza científica y jurídica de poder precisar desde cuándo se considera el inicio de la vida humana: con la fusión nuclear, con la formación del cigoto, con la anidación del embrión en el útero de la madre o con la simple concepción, ya que la vida es un devenir, un proceso que se inicia con la unión del ovulo y el espermatozoide, aun con la interrogante e inseguridad de que también se considere que hay vida humana cuando la unión sea extrauterina (fecundación in vitro).

2. La persona individual o natural que se refiere al ser humano una vez nacido, es decir, a partir del corte del cordón umbilical en adelante.

3. La persona colectiva o jurídica, constituida por ese conjunto o reunión de personas naturales e inclusive jurídicas que se agrupan para cumplir un determinado fin, sea lucrativo o sin fines de lucro, y que cumplen con todos aquellos requisitos formales exigidos por la ley para su inscripción.

4. Las organizaciones no inscritas.

No podemos dejar de señalar que para determinados juristas y ordenamientos jurídicos la expresión sujeto de derecho se refiere a todo ente vinculado con la vida humana; es decir, dicho término contempla la existencia de cuatro o más categorías jurídicas que siempre se encuentren relacionados con la vida humana. En palabras de Alfredo González Prada, «el derecho es esencialmente antropocéntrico»; hacía referencia a esta característica del derecho pero de un modo peyorativo, que será comprendido líneas más abajo.

Expresaba también Alfredo Gonzales Prada: «Dentro del concepto genuinamente clásico de la noción de sujeto de derecho, al hombre y solo al

3 Fernández Sessarego 1984: 72.

4 González Prada 1914: 14. 
hombre corresponde el goce de esta calidad: él representa el punto céntrico, alrededor del cual giran todas las normas jurídicas, el eje del sistema, la esencia: el derecho es esencialmente antropocéntrico». Sin embargo, señalaba: «El derecho, al lado del hombre, el sujeto jurídico por excelencia, admite otros: las personas morales, seres desprovistos de existencia física, mas no de la aptitud de tener derechos u obligaciones».

En este estado de cosas, y teniendo en cuenta el tema central de nuestro artículo - los animales-, haremos referencia a las teorías que representan puntos de vista radicales en cuanto al término sujeto de derecho, para comprender, siguiendo a Alfredo González Prada, lo que propuso en su investigación denominada El animal y el derecho.

Por su parte, el profesor y jurista francés Léon Duguit niega la existencia del término sujeto de derecho. Duguit ${ }^{5}$, citado por Alfredo González Prada, afirma:

Todos los hombres son seres sociales y, como tales, están obligados a obedecer la regla social, bajo pena de provocar contra ellos una reacción social. [...] Toda sociedad es una disciplina; y como el hombre no puede vivir fuera de la sociedad, no puede eximirse de vivir bajo esa disciplina. ¿Cuál es esa regla? Tiene como fundamento el hecho mismo de la solidaridad social, es decir, "el hecho de la interdependencia, uniendo a los miembros de la humanidad o a los de un mismo grupo social por la comunidad de las necesidades y la división del trabajo». [...] Sin duda que muy a menudo una situación jurídica subjetiva creada por un acto de voluntad se nos aparece exteriormente bajo la forma de una relación entre dos sujetos. Hasta puede afirmarse que la mayor parte de las veces acontece así. Pero aparecen frecuentemente en la vida de las sociedades modernas situaciones que deben ser jurídicamente protegidas y que sin embargo no envuelven una relación entre dos sujetos. ¿Es acaso necesario para explicar que esas situaciones se hallan jurídicamente protegidas suponer la existencia de esos sujetos y decir: si esta es una situación protegida, hay sujetos de derecho? ¿Por qué? [...] No cabe, pues, hablar de vínculo jurídico ni de sujeto de derecho: solo hay un individuo que quiere su provecho, el de un tercero o el de una colectividad. «No vemos — dice Duguitese vínculo jurídico entre dos supuestos sujetos. Hay una situación jurídica con un derecho y una obligación, mas no un vínculo entre el sujeto que tiene derecho y el sujeto que debe la obligación. [...] Ese concepto de derecho subjetivo, que algunos pretenden presentarnos como una verdad absoluta, no representa más que un momento en la historia eternamente cambiante de las instituciones y de las ideas; un momento culminante, pero nada más».

5 Ídem: 16-19. 
Por otro lado, al otro extremo, encontramos al jurista alemán Ernst Immanuel Bekker, quien consideró que la expresión sujeto de derecho debe ampliarse en su contenido. Afirma que encuentra dos entidades en el derecho: «el goce y el derecho de disposición. No debemos — dice- exigir de aquel que tiene el goce de algo otra cosa que la susceptibilidad de gozar, y no la capacidad de querer o de contratar; en una palabra, el carácter de ser humano. Basta para ser sujeto de derecho la aptitud de goce ${ }^{6} »$.

Siguiendo a Bekker podemos señalar que existen dos categorías de sujetos de derechos: aquellos que poseen la capacidad de goce, capacidad que adquieren, abarca y contiene a todos los seres dotados de sensibilidad, y a los sujetos que ostentan capacidad de disposición, característica que se concede de manera limitada y exclusiva al hombre.

Para Alfredo González Prada, «la calidad de sujeto de derecho está restringida, desde el punto de vista del goce, a todos aquellos que pueden aprovechar directamente del derecho, teniendo capacidad de experimentar placer o dolor. Equivale en una palabra a ampliar el concepto de subjetividad jurídica dentro de la noción de subjetividad moral, en la que, como dice Hoffding, "no hay necesidad de una razón elevada o de una vasta inteligencia: basta poseer la facultad de sentir o de sufrir. Ni la razón ni la voluntad son, pues, ya elementos esenciales de la subjetividad jurídica". [...] En la forma expuesta, el derecho se nos aparece como algo infinitamente hermoso, como la única fuerza capaz de realizar la enorme confraternidad del dolor, solidarizando en una dignificación excelsa toda la carne viva que sufre. [...] y, citando a Demogue, señala que "el derecho, esa cosa tan intelectual en apariencia, acudiendo para la realización de su fin a las facultades emocionales, viene a ser algo así como la comunión de los que sufren, como un inmenso sindicato de luchas contra el dolor de todos los seres. ¿La vida en el hombre merece acaso distinto respeto que la vida animal? Todos los seres tienen en igual grado el derecho a la existencia. Toca al derecho realizar la nivelación reparadora"7»».

Asumiendo la postura sostenida por Bekker y de una lectura concienzuda y meticulosa de la tesis de Alfredo González Prada, podemos manifestar que el goce le pertenece a todo ser vivo por el simple hecho de estar investido de facultades emotivas y, por ende, es en sí sujeto de derecho. «La personalidad del niño y del loco, tan difíciles de explicar, fluyen de esta concepción con toda lógica; el animal, capaz de reacciones psíquicas dolorosas o agradables, se eleva a idéntico nivel de personalidad jurídica 
que los mismos seres humanos incapaces de funciones intelectuales $y$ volitivas ${ }^{8} \gg$.

No cabe duda de que los animales no humanos carecen de capacidad de disposición, pero, acaso, no se encuentra científicamente demostrado que los animales son seres que sienten y experimentan dolor. Por ende, nos surge la interrogante: ¿estaríamos los seres humanos — los animales humanos - dispuestos a conceder a los animales no humanos la categoría jurídica de ser considerados sujetos de derecho? Empero, nosotros seres humanos, justamente por ser seres que poseemos capacidad cognoscitiva y raciocinio, debemos entender que esos seres, los animales no humanos, merecen respecto, consideración y protección justamente por ser sujetos y no meramente objetos de derecho.

\subsection{En cuanto a la categoría jurídica de ser objeto de derecho}

Según la Real Academia Española, el término cosa presenta varias acepciones desde el punto de vista del derecho y filosóficas a citar: «1. f. Todo lo que tiene entidad, ya sea corporal o espiritual, natural o artificial, real o abstracta. 2. f. Objeto inanimado, por oposición a ser viviente. 5. f. Der. En contraposición a persona o sujeto, objeto de las relaciones jurídicas. En el régimen de esclavitud el esclavo era una cosa. 6. f. Der. Objeto material, en oposición a los derechos creados sobre él y a las prestaciones personales. 7. f. Der. Bien». Y el término bien, según la Real Academia Española, significa: «Der. Cosas materiales o inmateriales en cuanto objeto de derecho».

El término cosa, desde el aspecto jurídico, es «el objeto primordial de las relaciones jurídicas-reales. Por cosa se suele entender toda realidad del mundo exterior que posee una existencia material. Sin embargo, esta somera idea implica muy diferentes cuestiones. Así, el concepto de cosa, en orden a su aplicación al campo del derecho, se ha buscado a través de conceptos ajenos al derecho, como pueden ser los conceptos de las ciencias naturales o físicas y los de la filosofía?».

Davide Messinetti, citado por Juan Espinoza Espinoza ${ }^{10}$, advierte que el término objeto puede tener dos nociones: «una de carácter general, en la cual objeto es todo aquello que es externo respecto a un punto de observación determinado y, por consiguiente, el objeto del derecho es la realidad misma. La otra acepción, de carácter restrictivo, reserva este término para indicar al objeto específico de una tutela atribuida al sujeto».

8 González Prada: 24.

9 Díez-Picazo 2007.

10 Espinoza Espinoza 2006. 
El bien, como objeto de derecho real, es toda entidad corporal (material) o incorporal (inmaterial), determinado, susceptible de valor económico, del cual se puede servir el ser humano para la satisfacción de sus múltiples necesidades.

Bien es todo lo que puede entrar y salir del patrimonio de las personas, aumentándolo o disminuyéndolo. «El bien tiene relevancia jurídica, por su posibilidad de ser objeto de relaciones jurídicas. Conforme a las exigencias de la realidad social, el ordenamiento jurídico es el que establece qué entidades materiales o inmateriales pueden ser objeto de derechos reales» ${ }^{11}$.

Biondi, citado por Francisco Avendaño Arana ${ }^{12}$, señala las características que deben reunir los bienes: «a) El bien es diferente del sujeto. La noción de bien se contrapone a la de persona, como sujeto de relaciones jurídicas. Las personas o su fuerza de trabajo (distinta de su resultado) no son bienes. b) El bien es un concepto que tiene relevancia jurídica. Lo que es indiferente al ordenamiento legal no es bien. La relevancia jurídica, es decir, el interés, la impone la ley. Cosa alude a entidad considerada objetivamente en sí misma. Bien, en cambio, se refiere al interés, a la ventaja o utilidad que otorga a una persona. Por tanto, su consideración es subjetiva. c) El bien proporciona utilidad. Los bienes deben ser útiles a los hombres en sus relaciones sociales. La utilidad puede ser de diversa índole, como material o moral. Para que los bienes sean útiles, deben ser susceptibles de apropiación. d) Los bienes son susceptibles de apropiación, independientemente de que dicha apropiación sea actual. Su apropiación depende en gran medida no solo de la naturaleza misma de la entidad, sino del nivel de tecnología imperante. En la actualidad la energía eléctrica, la magnética y la calorífica son bienes en la medida en que son apropiables. e) El tráfico de los bienes debe ser lícito. El tráfico debe estar permitido por el ordenamiento legal. Hay objetos cuyo tráfico está prohibido legalmente, que están fuera del comercio. Para que podamos hablar de bienes fuera del comercio, cualquier acto jurídico respecto del bien debe ser ineficaz. Una persona, por ejemplo, no puede ser objeto de tráfico. Cualquier acto jurídico respecto de ella no produciría efecto. En cambio, la comercialización de estupefacientes no implica necesariamente la ineficacia del acto (sin duda que origina una sanción penal). Por licitud del tráfico se refiere a lo primero. f) Los bienes pueden ser futuros. Los bienes pueden no tener existencia presente. g) Los bienes tienen valor económico. Los bienes, como objeto de los derechos reales, deben ser susceptibles de satisfacer un interés económico». 
Según nuestro vigente Código Civil de 1984, los animales, aunque, no lo prescriba expresamente, debido a su capacidad de trasladarse de un lugar a otro sin ayuda de una fuerza externa o exterior, son considerados como bienes muebles - semovientes - o cosas corpóreas.

Es así que son tratados como objetos del derecho; es decir, son seres vivos que pueden ser aprovechados y utilizados por el hombre (otro ser vivo) y que poseen un valor económico.

En ese sentido, el derecho confiere a sus propietarios o titulares, otros seres vivos o animales humanos, todos los atributos del derecho de propiedad: servirse del animal de acuerdo con su naturaleza o destino (usar), aprovecharse económicamente del animal (disfrutar), desprenderse o prescindir del animal (disponer) y el de recuperarlo (reivindicación) según las circunstancias:

No obstante ello, incluso como objetos de derecho, históricamente los animales han ocupado un lugar importante dentro del derecho. En el orden natural, todo animal era res nullius, es decir, una cosa que no pertenecía a nadie. A diferencia de una res commune (como el aire o el agua), una res nullius podía formar parte de la propiedad privada mediante la aprehensión [...]. Todos los sistemas legales desarrollaron elaboradas normas de responsabilidad que establecen tanto la responsabilidad del propietario por los daños cometidos a sus animales, como el derecho del propietario a ser indemnizado por los daños causados a sus animales [...]. Ser propiedad de los humanos cambia el estado natural de los animales tanto para mejor como para peor. Debido a que los humanos utilizan y valoran a los animales, los propietarios gastan recursos en su protección. La propiedad privada de muchas mascotas (o, si es necesario, «compañeros») les permite acceso a alimento y refugio (y algunas veces a vestimenta), lo cual origina vidas largas, tranquilas y cómodas ${ }^{13}$.

Nosotros, los seres humanos, ¿debemos seguir aceptando que los animales sean calificados como objeto de derecho de los animales humanos? ¿Podemos seguir admitiendo que los animales no humanos, seres que tienen vida y que poseen capacidad de sentir, sean usados como bienes sujetos al control de los seres humanos? ¿Es acaso novedad que los animales no humanos se reproduzcan, generen vida, alimenten, protejan, sientan y sufran, y a pesar de ello se los trate simplemente como si se tratara de otro bien mueble? «Los animales no son iguales que cualquier objeto inanimado como un vaso o una jarra. Estos seres vivos no solo tienen una existencia evidente, sino que, además, como ha sido comprendido 
por los estudiosos, cuentan con emociones y son susceptibles de irritarse, agredir, respectar o violar territorios» ${ }^{14}$.

\subsection{Los Códigos Civiles europeos}

La mayoría de los Códigos Civiles europeos coinciden en la calificación jurídica de los animales como cosas en propiedad. Sin embargo, cabe resaltar que en los Estados miembros de la Unión Europea se vienen dando directivas que de manera expresa favorecen la promulgación de leyes a favor de los animales, amparados sobre todo en su calidad de seres sensibles distintos de los bienes desprovistos de vida. Tres Estados de la Unión Europea (Austria, Alemania y Suiza) han modificado sus respectivos Códigos Civiles y sus Constituciones, reformando el estatuto de animal-cosa. Estos Estados son Austria (ABGB 1988; Constitución 2004), Alemania (BGB 1990; Constitución 2002) y Suiza (BGB 2000; Constitución 2004)

Austria: La ley del 1 de julio de 1988 introdujo el apartado 285a, que excluía a los animales de la consideración de cosas en propiedad. Los animales no son cosas; están protegidos por leyes especiales. Las disposiciones referidas a las cosas se aplican a los animales, en caso de no existir una previsión diferente.

Según Teresa Giménez-Candela ${ }^{15}$, «el cambio jurídico operado en Austria despertó un gran interés y tuvo una inmediata repercusión en Alemania, donde no se tardó (1990) en llevar a cabo una reforma de carácter semejante. Sin embargo, puede decirse que fue una reforma de carácter superficial, en primer término porque se adoptó una formulación negativa: el animal no es una cosa, lo que provoca indefinición e imposibilita extraer todas las consecuencias que se siguen de tal formulación; en segundo término, porque el mismo parágrafo incurre en una contradicción flagrante al declarar que los animales no son cosas y que están protegidos por leyes especiales, pero (segunda parte) se les aplican las reglas destinadas a las cosas, en caso de no existir una norma específica para ellos».

Alemania: Después de dos años de la reforma del Código Civil Austriaco, se reformó el BGB mediante la Ley para la Mejora de la Situación Jurídica del Animal en el Derecho Civil, lo que produjo una cadena de reacciones entre la euforia y la crítica acerba, pues los cambios introducidos, siguiendo el modelo de Austria, no variaron sustancialmente la posición de los animales como objetos de derecho. Al artículo 90, que contiene el concepto de cosas en sentido jurídico, se añadió un 90a, destinado a los animales: «Artículo 90. Cosas, en el sentido de la ley, son solo las cosas

14 Ídem.

15 Giménez-Candela s. f. 
corporales. Artículo 90a. Los animales no son cosas. Están protegidos mediante leyes especiales. Se les aplicarán las disposiciones vigentes para las cosas, siempre que no haya otra previsión».

Advertimos que la modificación es bastante semejante a la del Código Civil Austriaco, pues, se señala que a los animales se les seguirá aplicando las normas relativas a las cosas, en el supuesto de no haber previsión específica para ellos. Sin embargo, hay que reconocer que la legislación alemana se modificó con coherencia para poder hacer eficaz la nueva condición de los animales, declarados no-cosas. Así, concretamente: en relación con los derechos y deberes de los propietarios del artículo 903, agregó: «El propietario de una cosa puede hacer uso de ella a su gusto, siempre que no vaya en contra de la ley o los derechos de terceros, y puede excluir a los demás de toda intervención. El propietario de un animal ha de observar, en el ejercicio de sus poderes, las previsiones especiales para la protección de los animales» ${ }^{16}$.

Distingue aquí con claridad el legislador los derechos inherentes a la propiedad —en cuanto al uso ilimitado que corresponde al propietario-, del ejercicio de estos por el propietario de un animal, quien debe atenerse a las normas específicas protectoras de los animales. Sin embargo, con toda su precisión, la observación deja una profunda insatisfacción, pues los animales-no-cosas en el BGB no han salido de la relación de propiedad y esta solo se ejerce sobre las cosas. Una contradicción patente, por muy coherente, técnicamente, que esté formulada. Pero quizá la modificación que ha hecho de Alemania un ejemplo destacado en el tema de protección animal es el cambio introducido por el artículo 20a, en la propia Constitución (Grundgesetz, GG), en el ámbito referido a la protección de los fundamentos naturales de la vida ("Schutz der natürlichen Lebensgrundlagen») en 2002: «Artículo 20a. [Protección de los fundamentos naturales de la vida y de los animales]. El Estado, asumiendo igualmente su responsabilidad respecto a las generaciones futuras, protege los recursos naturales y a los animales por medio del ejercicio del Poder Legislativo, en el cuadro del orden constitucional y de los poderes ejecutivo y judicial en las condiciones que establezcan la ley y el derecho».

Suiza: Suiza se distingue de otros ordenamientos, por extender la protección a todas las criaturas vivientes, incluyendo a las plantas, sobre la base de la declaración de la dignidad de las mismas («Würde der Kreatur»). No se trata de una declaración que incida en la obligación moral del ser humano de respetar la naturaleza, sino que, desde hace más de 30 años, 
constituye una obligación de carácter constitucional acogida y refrendada por la legislación tanto federal como cantonal, para optimizar la aplicación y la inserción en la normativa de las restricciones y condiciones de protección de los animales.

El concepto de dignidad de las criaturas tiene su anclaje en las ideas del filósofo danés Lauritz Smith (1791) y del teólogo de Basilea Karl Barth, quien en 1945 formuló la idea de que los animales tienen una dignidad propia, merecedora de protección. 


\section{REFERENCIAS BIBLIOGRÁFICAS}

AVENDAÑO ARANA, Francisco (2004, enero). «Código Civil comentado». En Gaceta Jurídica, tomo V.

CLAUS, Roxin (1997). Derecho penal. Parte general. Fundamentos de la estructura del delito. Madrid: Civitas.

DÍEZ-PICAZO, Luis (2007). Fundamentos del derecho civil patrimonial. Navarra: Thomson Civitas.

ESPINOZA ESPINOZA, Juan (2006). Derecho de las personas. Lima: Editorial Rodhas.

FERNÁNDEZ SESSAREGO, Carlos (1984). La persona en la doctrina jurídica contemporánea. Lima: Universidad de Lima.

FOY VALENCIA, Pierre Claudio (2010). Impacto de los nuevos saberes éticocientíficos acerca de los animales en los sistemas jurídicos. Una aproximación. Cuaderno de Trabajo 19. Lima: Departamento Académico de Derecho de la Pontificia Universidad Católica del Perú.

GIMÉNEZ-CANDELA, Teresa (s. f.). «Informe sobre los animales en el derecho civil: cuestiones básicas para una legislación macro en bienestar animal». En https://www.psoe.es/source-media/000000484000/000000484368.pdf. Consultado el 11 de junio de 2011.

GONZÁLEZ PRADA, Alfredo (1914). El derecho y el animal. Tesis para el doctorado en Jurisprudencia. Lima: Imprenta Artística Calonge.

RODRÍGUEZ GARCÍA, Gustavo (2008). «Animales... ¿en peligro de extinción o en peligro de que los extingamos?». En lus et Praxis, nro. 1, vol. 14.

TORRES VÁSQUEZ, Aníbal (2006). Derechos reales. Lima: Idemsa.

Recibido: Febrero de 2012.

Aceptado: Julio de 2012. 